\title{
$(119049)$
}

\section{VLAAMSE KOLENSCHEPEN \\ EN SCHONENSE KAAKHARING \\ TE NEWCASTLE UPON TYNE \\ (1377-1391)}

Roger DEGRYSE

Newcastle upon Tyne was in de late middeleeuwen ongetwijfeld de voornaamste haven van Noordoost-Engeland voor de uitvoer over zee van de aldaar in de open mijnen ontgonnen steenkool of zeekolen. Eenmaal in de handel, in de 13de eeuw, werd deze grondstof in Engeland en op het vasteland voor allerlei industriële doeleinden aangewend, waaronder vooral als brandstof voor de produktie van kalk in de kalkovens en de bewerking van ijzer in de smidsen'. In Vlaanderen sprak men dan ook, in verband daarmee, van "smeidecolen» of «carbon de fevre»². In een interessant artikel heeft de heer J.B. Blake de ontwikkeling van het steenkolenbedrijf te Newcastle upon Tyne in de 13de en 14 de eeuw nagegaan ${ }^{3}$. Aangezien zijn bevindingen niet alleen voor Engeland zelf, maar ook voor Vlaanderen, benevens Zeeland, Holland en de hanzehavens van belang zijn, loont het de moeite om, meer bepaald voor wat het aandeel van de Vlaamse vloot in de export van

1. L.F. SALZMAN, English trade in the Middle Ages. Oxford, 1931, p. 281282.

2. Op 5 augustus 1410 diende de magistraat van Nieuwpoort een vertegenwoordiger naar Brugge te sturen «an de wet omme Michiel Boudenszoens wille, wien d Inghelsche een scip met smeide colen ghenomen hadden ende ghevoerd te Calays". Brugge, Rijksarchief, fonds Oud Archief Nieuwpoort, nr. 3504, stadsrek. $1410-1411, \mathrm{f}^{\circ} 29 \mathrm{r}^{\circ}$.

3. J.B. BLAKE, The medieval coal trade of North East England: some fourteenth century evidence, in Northern History. A review of the history of the North of England. The University of Leeds, vol. II, 1967, pp. 1-26. 
Vlaamse kolenschepen en Schonense kaakharing

steenkool uit deze Engelse haven betreft, nader op de door hem onderzochte gegevens in te gaan en ietwat aan te vullen. Aan te stippen is, dat voor de aanduiding van de hoeveelheden ingeladen, vervoerde of verhandelde steenkool men te Newcastle upon Tyne en elders in Engeland, als inhoudsmaat of rekeneenheid, de «chaldron» of "chaudron» gebruikte. Deze kwam, althans in die tijd, neer op een gewicht van 1800 tot 2000 pond of ongeveer 900 kilo, wat zowat overeenstemde met het gewicht van een vat wijn of een halve last haring. Ze telde als rekeneenheid vier «quarters» of vierden, die, naar gelang de te meten droge koopwaar en soms ook naar gelang de streek, elk uit 8 tot 10 «bushels» bestonden ${ }^{4}$.

De eerste maal, dat we van een Vlaamse scheepslading steenkolen, blijkbaar uit Newcastle upon Tyne, gewag horen maken, is in 1273. Dat jaar, op 29 september, werd in de haven van Orwell de «nef» van Simon Cemp uit Grevelinge met zulk een vracht, bedragende 63 "chaldrons", ter waarde van 50 s. sterling, benevens met lakens en harnassen, door lieden van Hartlepool en elders in beslag genomen ${ }^{5}$. Het is inderdaad aanvankelijk alleen naar aanleiding van zulke konfiskaties of gevallen van kaping en zeeroverij door de Engelsen, dat we over de Vlaamse trafiek met in Engeland ingeladen kolen iets vernemen. Zo zien we in 1313 of daaromtrent te Newcastle een Duinkerks schip met een draagvermogen van wel 100 wijnvaten, dat er de haven aangedaan had om kolen in te laden, door de overheid in beslag genomen en verkocht worden en dit op verzoek van lieden van Beverley wegens schade hen op zee

4. SALZMAN, p. 48 - BLAKE, p. 2, n. 7. - J.U. NEF, The rise of the British coal industry. London, 1932, II, app. D en E.

5. «Simun Cems de Grevelinglime (sic) eut en arret au port de Rowelle par Luke le Merchant (et Henry ?) de Hertepol e lur compainuns de (Wytdelerse) une nef, pris $10 \mathrm{lb}$. Item 63 celders de carbon, pris (50) s. Item dras et armures, pris $20 \mathrm{~s}$. e ce a (ete) prove par le serment ...... Mikel le Maire et Henri fil Beeson a le Saint Mikel 1 an 73. Summa 13 lb. 10 s. "Londen, Public Record Office, Various Accounts Exchequer E 101, nr 127 / 3. Beschadigde rol. Zie item 12. - C. WYFFELS, De Vlaamse handel op Engeland vóór het Engels-Vlaamse konflikt van 1270-1274, in Bijdr. voor de Gesch. der Ned., dl. XVII, 1963, nr. 3, p. 205-213, aantekening. Zie p. 211, ontleding. - In item 14 lezen we "Simon Cemp» in plaats van S. Cems. Mikel le Maire en Henri fil Beeson waren eveneens stuurlui uit Grevelinge. 
door Vlaamse kapers of zeerovers toegebracht ${ }^{6}$. Daar waren ook de incidenten in verband met de uitvoer naar Vlaanderen, op Engelse of Vlaamse vaartuigen, van smokkelgoed, waaronder naast wol, soms een lading steenkolen uit Newcastle. Op de export van goederen drukten inderdaad in de Engelse havens zekere "customs» of tollen, aan de betaling waarvan men zich niet straffeloos mocht onttrekken. Bovendien moesten sommige grondstoffen, waaronder de wol en soms ook de kolen, bestemd voor het vasteland, wettelijk verplicht langs een stapelplaats, gevestigd in Engeland zelf of op het vasteland, doorgevoerd worden. Sinds 1372 fungeerde als dusdanig permanent de havenstad Kales, die door de Engelsen op de Fransen veroverd geworden was. Deze stapeldwang, die vooral diende om de Engelse koninklijke schatkist te spijzen, was hinderlijk voor het vrij verloop van de handelstrafiek, niet alleen van de Vlaamse, maar ook van de Engelse zelf. Vandaar dan ook de poging in 1378 door de kooplui van Newcastle bij de koning ondernomen om van hem vrijstelling van de verstapeling te Kales te bekomen, daar de verkoop en ontlading van de aangevoerde voorraden steenkool er, wegens gemis aan afzetmogelijkheden, niet steeds kon plaats vinden ${ }^{7}$. Op dit verzoek werd blijkbaar door de vorst ingegaan, vermits van die tijd af opnieuw alle

6. «Henrys Culkin, borgois de Dunkerke, se deult el nom jadit Jehan Culkin, sen pere, dou damage que ses peres eut de cheaus dEngleterre et specialement chil de Beverle et chil dou Casteel sour Tyne et en temps de paes, car il avoit une nef, le quelle il fist faire tout de novel et portoit bien chends tonels de vin ou plus, le quelle nef, quant elle fut tout estofee et appellie, il envoia au Casteel dessus dit pour illeuques kerkier carbon de fevre et quant la dite nef est arivee ens en 1 ewe ou dit Casteel, ont envoie chil de le ville de Beverle... et le ont fait arrester... Et vaut bien la dite nef, si comme elle ala comment qu elle fu vendue, $40 \mathrm{lb}$. esterlins... Et fut la dite nef arestee et vendu passe a 6 ans ou la entour...». Gent, Rijksarch., fonds de Saint-Genois, nr. 1374, 2de stuk. Klaagschrift van omstreeks 1319. Niet gedateerd. Volledige tekst in R. DEGRYSE, La pêche et la marine dunkerquoises vers 1300, in Meded. v.d. Mar. Ac. v. België, dl. XIII, 1961, p. 21-32. Zie p. 23 en 25-26, bijlage II.

7. BLAKE, p. 6-7 en 14-15. - De wolstapel te Kales was eigenlijk in 1363 ingesteld geworden, maar als gevolg van de vijandelijkheden met Frankrijk kon hij aanvankelijk niet bestendig in werking blijven. Eerst in $1372 \mathrm{kwam}$ daarin verbetering. Daarna waren er soms nog onderbrekingen. E. PERROY, L'administration de Calais en 1371-1372, in Revue du Nord, dl. XXXIII, 1951, p. 218-227. - J. LULVÈS, Calais, sous la domination anglaise, 1347-1558. Bern, 1917. 
schepen direct van uit de haven van Newcastle steenkool naar vreemde landen mochten verschepen. Dit belette niet dat op deze uitvoer een tol «ad valorem» ten bedrage van 3 penningen per pond sterling bleef drukken Deze heffing vinden we genoteerd in de rekeningen van die "custom», die, van 1377-1378 af, voor bepaalde jaren of periodes bewaard gebleven zijn. Een viertal van deze bescheiden, de oudste, namelijk die over de boekjaren 13771378, 1380-1381, 1381-1382 en 1390-1391, werden door J.B. Blake geanaliseerd en besproken ${ }^{8}$. De items, die ze opsommen, hebben we op onze beurt, meer in het bijzonder voor de Vlaamse schepen, terug nagegaan, ten einde enkele statistische tekorten in het artikel van deze auteur aan te vullen.

Op te merken eerst en vooral is dat de Newcastle op ál de goede ren, die er door de vaartuigen gelost werden, de tol "ad valorem» van $3 \mathrm{~d}$. per pond sterling drukte. In de bewuste rekeningen worden dan ook achtereenvolgens per schip opgesomd de datum van aankomst of van vertrek, zoniet beide data, de naam en de plaats van herkomst van het vaartuig, de naam van de stuurman of schipper, het geloste goed, diens handelswaarde en de daarvoor betaalde tol, de ingeslagen hoeveelheid steenkolen, berekend in "chaldrons", met de waarde ervan, en de daarvoor vereffende tol. Daar J.B. Blake in zijn berekeningen niet alle Vlaamse havenplaatsen weerhoudt, blijkbaar omdat hij die niet allemaal kent, zijn de door hem gemaakte statistische tabellen niet steeds volledig. Hij houdt inderdaad alleen rekening met de schepen herkomstig uit Duinkerke, Nieuwpoort, Oostende, Heist, Sluis en Brugge. In de door hem geraadpleegde bescheiden is er nochtans soms ook sprake van vaartuigen uit Grevelinge, de Nieuwe IJde, Lombardsijde, Walravensijde, Nieuwerhaven en Biervliet. Dit althans voor wat de uitvoer van steenkolen aangaat. Daarnaast wordt één keer Hugevliete vermeld, maar dan in verband met de invoer van gezouten haring. Overigens laat J.B. Blake de import van allerlei koopwaren door de aanleggende schepen buiten beschouwing en dit

8. BLAKE, p. 17-20. - London, P.R.O., reeks E 122/106, nrs. 1, 4, 5 en 21. - We bedanken het Public Record Office voor het sturen van de fotokopieën van deze rollen. 
is ook zo voor de uitvoer van andere zaken dan zeekolen, waaronder molenstenen.

De alleroudste en voor de Vlaamse navigatie op Newcastle interessantste van de vier genoemde rekeningen loopt over het boekjaar eind september 1377 - eind september 1378. Tijdens deze periode werden door vaartuigen uit Vlaanderen, Zeeland, Holland en de hanzeatische havens in het totaal, volgens onze eigen berekening, 7586 «chaldrons» steenkool in 159 scheepsladingen te Newcastle ingescheept en uitgevoerd. Het aandeel van de Vlamingen daarin was als volgt ${ }^{9}$ :

\begin{tabular}{lrrr}
\hline Haven of ijde van & Werkelijk aantal & Aantal scheeps- & Hoeveelheid \\
herkomst van het schip & deelnemende schepen & ladingen steenkool & in "chaldrons"
\end{tabular}

$\begin{array}{lrrc}\text { Grevelinge } & 1 & 2 & 92 \\ \text { Duinkerke } & 17 & 21 & 952 \\ \text { Nieuwpoort } & 21 & 27 & 12168 \\ \text { Lombardsijde } & 6 & 8 & 346 \\ \text { Walravensijde } & 3 & 5 & 202 \\ \text { Oostende } & 2 & 3 & 98 \\ \text { Heist } & 14 & 19 & 954 \\ \text { Sluis } & 10 & 12 & 652 \\ \text { Brugge } & 1 & 1 & 34 \\ \text { Nieuwerhaven } & 5 & 6 & 270 \\ \text { Totaal } & 80 & 104 & 4816\end{array}$

9. Zie bijlage - BLAKE, p. 17-18, waar een totaal, voor al de ladingen, van 7320 "chaldrons» aangegeven staat. Genoemde auteur kwam voor Heist slechts tot een totaal van 18 ladingen van samen 906 «chaldrons». Blijkbaar hield hij geen rekening met een schrijffout in item 107, waar sprake is van de uitvoer van 48 molenstenen door een vaartuig uit Heist en waar men kennelijk in de plaats 48 "chaldrons" had moeten schrijven, wat uit de waarde van de vracht af te leiden is. Blake laat voor dat boekjaar in zijn bespreking de schepen uit Grevelinge, Lombardsijde, Walravensijde, Oostende en Nieuwerhaven buiten beschouwing, maar laat hun vrachten steenkolen wel meetellen. 
Gaan we de omvang van de Vlaamse kolentrafiek vanuit Newcastle gedurende elk van de twaalf maanden van het bestudeerde boekjaar na, dan bekomen we volgende statistiek :

oktober 1377

november

december

januari 1378

februari

maart

april

mei

juni

juli

augustus

september

Totaal 12 maanden
9

1

9

2

14

2

15

23

26

3

104
424

39

429

88

695

97

660

1028

1184

172

4816

Tijdens de hier besproken periode van twaalf maanden hadden te Newcastle sommige Vlaamse schepen ook koopwaar gelost, vooraleer er te vertrekken met of zonder een lading steenkool aan boord. De betrokken rekening van de «custom» somt al deze vaartuigen op. Zo komen we de plaats van herkomst te kennen van nog vier schepen uit Vlaanderen, die gedurende genoemd boekjaar Newcastle bezocht hadden, maar er geen kolen exporteerden, namelijk Nieuwerhaven twee vaartuigen en Sluis en Nieuwpoort elk een vaartuig ${ }^{10}$. Wat door de Vlamingen te New-

10. Nieuwerhaven : toenmaals nieuwe aanlegplaats tussen Breskens en Gaternisse. M. COORNAERT, Knokke en het $Z$ win. Tielt, 1974, p. 361, kaart nr. 8. 
castle ingevoerd werd, woog in vracht en in waarde evenwel niet op tegen hetgeen ze er aan steenkool uitvoerden. Zo bestond de importlading van acht Nieuwpoortse schepen uit tegels, waarvan in vier gevallen elk de hoeveelheid 4.000 stuks bedroeg met een waarde van 10 schellingen sterling, wat slechts de tegenwaarde van vijf «chaldrons» steenkool vertegenwoordigde. Ook twee vaartuigen uit Lombardsijde hadden elk zulk een hoeveelheid tegels te Newcastle gelost. Tegels waren er bovendien eveneens door twee Duinkerkse schepen ingevoerd, zodat we ons de vraag mogen stellen of er soms geen verband tussen die import en de uitvoer van steenkool kan bestaan hebben, namelijk het gebruik van laatstgenoemde brandstof in de steenbakkerijen van de Vlaamse kust. Overigens zou men zich ook kunnen afvragen of de door de Vlamingen in hun vaartuigen meegevoerde tegels soms niet als ballast dienden, althans zolang als de in te slaan steenkolen niet ingeladen waren $^{11}$. Tot de andere weinig talrijke produkten, die door de Vlaamse schepen gedurende de besproken periode te Newcastle gelost geworden waren, behoorden teer, pek, kurk, bast of uit bast gevlochten touwen, wagenschot, linnen, zout en een pijp azijn. Een vaartuig uit Duinkerke had er 200 stuks aardewerk ontladen en een ander uit Heist zes bootmasten ${ }^{12}$. Aan de invoer van deze goederen hadden in het geheel slechts 31 van de 84 toen te Newcastle binnengevaren Vlaamse vaartuigen deelgenomen. Wat de reisroute en het tijdsgebruik van al deze schepen, vanaf hun vertrek uit Vlaanderen tot aan hun terugkeer aldaar kunnen geweest zijn, weten we niet, alhoewel dit misschien, althans gedeeltelijk en fragmentarisch, aan de hand van de gegevens in andere gelijktijdige rekeningen van de «customs» in de Engelse havens na te gaan is ${ }^{13}$. Opmerkelijk nochtans is wel dat vooral in juni, juli en augustus, d.i. de periode van de vangst van zomerharing, door de Vlaamse vaartuigen te Newcastle aangelegd en steenkool ingeladen

11. Ibidem, items 57, 58, 59, 118, 119, 120, 129, 130, 131, 170, 191.

12. Ibidem, items 8, 15, 33, 34, 61, 72, 81, 115, 117, 134, 149, 162 en 194.

13. De afstand tussen Nieuwpoort en Newcastle upon Tyne bedraagt zowat 600 kilometer. Op deze route lagen havens als Dover, Sandwich, Orwell (Harwich), Orford, Great Yarmouth, Kings Lynn, Boston, Grimsby, Ravenser, Withernsea, Filey (Fiveley), Scarborough, Whitby, Hartlepool en Tynemouth. 
was. Daaruit zou dan wellicht afgeleid kunnen worden, dat de Vlaamse kolentrafiek vanuit Newcastle jaarlijks in het kader van de zeevisserijcyclus plaatsgreep. Dit zou tevens verklaren waarom in september, als gevolg van het naken van de teelt of vangst van herfstharing, genoemde kolentrafiek grotendeels uitviel. De haringvisserij voor de kust van Zuidoost-Engeland verliep inderdaad, naar gelang het voortschrijden van het jaar, meer en meer zuidwaarts tot voor de Vlaamse kust, waar ze eindigde ${ }^{14}$.

Tot welk scheepstype behoorden de vaartuigen van Sluis en de Vlaamse kusthavens en vissersplaatsen, die aan de kolenexport uit Newcastle deelnamen ? Een duidelijk antwoord op deze vraag geeft de onderzochte rekening niet. Wel mogen we aanvaarden dat uit de lading steenkool, uitgedrukt in "chaldrons», van elk schip, diens tonnenmaat afgeleid kan worden, althans approximatief, daar zulk een vracht niet steeds het volledig draagvermogen van het vaartuig weerspiegelt. Dit blijkt uit de ladingen van de 21 Vlaamse schepen, die gedurende de betrokken periode hetzij tweemaal, hetzij zelfs drie keer te Newcastle kolen ingeladen hadden, waarbij soms een marge van 15 «chaldrons» vastgesteld kan worden. Meestal nochtans was dit verschil niet groter dan 6 "chaldrons». In enkele gevallen evenwel had hetzelfde vaartuig telkens dezelfde hoeveelheid steenkool ingescheept ${ }^{15}$. Houden we,

14. De Vlaamse haringvissers deden in normale omstandigheden jaarlijks tussen mei en september hoofdzakelijk de havens Scarborough en Whitby aan om er hun vangsten te lossen, vooraleer verder zuidwaarts af te reizen. Dit gebeurde tijdens hun reizen noordoverwaarts vóór de «teelt». In Normandië heette men zulk een reis «saffare», naar het Engels woord «seafare», d.i. zeereis of vangstreis. Gedurende de noordoverreis werd door de Vlaamse vissers blijkbaar ook of misschien zelfs vooral aan vrachtvaart gedaan, meer bepaald aan vervoer van zout voor import in de Engelse havens. In dit kader moet dan ook wellicht de export van kolen op de terugweg naar Vlaanderen gezien worden. R. DEGRYSE en O. MUS, De laatmiddeleeuwse haringvisserij in Bijdr. Gesch. Nederl., dl. XXI, 1966-1967, nr. 2, p. 82-121. Zie p. 85-94, evenals p. 114-120, bijlagen.

15. Bijlage, items 15 en $23(\mathrm{~S}), 18$ en $19(\mathrm{NH}), 46$ en $131(\mathrm{~N}), 48,86$ en $119(\mathrm{~L})$, 63 en $188(\mathrm{~S}), 67$ en $107(\mathrm{H}), 77$ en $178(\mathrm{D}), 79$ en $175(\mathrm{~N}), 82$ en $166(\mathrm{H}), 85,105$ en $138(\mathrm{H}), 87$ en $137(\mathrm{H}), 95$ en $177(\mathrm{~N}), 106,136$ en $182(\mathrm{~W}), 111$ en $174(\mathrm{D})$, 113 en $193(\mathrm{O}), 115$ en 155 (D), 117 en 172 (N), 129 en 163 (N), 135 en 179 (W), 156 en 187 (D) en 158 en 195 (G). Vijf eenheden uit Nieuwpoort (N), vier uit Duinkerke (D), vier uit Heist $(\mathrm{H})$, twee uit Sluis (S), twee uit Nieuwerhaven (NH), twee uit Walravensijde (W), een uit Lombardsijde (L), een uit Oostende $(O)$ en een uit Grevelinge $(G)$ hadden dus elk twee of zelfs drie maal Newcastle aangedaan om er nadien met een lading kolen te vertrekken. 
voor wat de 21 genoemde schepen aangaat, alleen rekening met de hoogste lading, die ze elk uitgevoerd hadden, dan zien we dat die in de meeste gevallen zowat 40 «chaldrons» bedroeg en de 60 «chaldrons» of daaromtrent zelden overschreed, wat op een draagvermogen van ongeveer evenveel vaten wijn neerkwam ${ }^{16}$. Dat was, voor zover we het kunnen nagaan, blijkbaar ook zo voor de overige vaartuigen, die te Newcastle slechts één keer steenkool ingeladen hadden. In het totaal kunnen er dan zowat 65 van de 80 betrokken eenheden zulk een tonnenmaat gehad hebben. Voor het overige hadden, steeds volgens onze berekening, zowat negen eenheden elk een tonnenmaat van wat minder dan 40 "chaldrons" of vaten en een zestal een van meer dan 60 "chaldrons» of vaten. De hoogste lading steenkolen, namelijk 95 "chaldrons", was door een schip uit Sluis, dat voordien zout en kurk gelost had, ingescheept en dit dan nog met een evenwichtige handelsbalans. Daarop volgden nog twee vaartuigen uit Duinkerke, waarvan de hoeveelheid ingeladen kolen telkens 80 «chaldrons» bedroeg, en een eenheid uit Sluis met een scheepslading van 70 «chaldrons» steenkool. De twee andere schepen, die elk respectievelijk 63 en 66 "chaldrons" kolen ingeslagen hadden, kwamen uit Nieuwpoort ${ }^{17}$. Van deze zes vaartuigen met elk een lading van meer dan 60 «chaldrons» kolen, behoorden ongetwijfeld de vier eerste tot het type van het koopvaardijschip en de twee Nieuwpoortse tot dit van het grote haringschip. Dit wil nochtans niet zeggen dat er onder de 74 overige eenheden geen andere vaartuigen dan vissersboten of haringschepen zouden geweest zijn, integendeel. Althans van een van hen, namelijk de «Juliane» uit Nieuwpoort, die achtereenvolgens met een lading van 36 chaldrons en een van 30 Newcastle verlaten had, mogen we misschien veronderstellen, dat het om een «eeverkine» ging, vermits zijn stuurman, Boudewijn Hallyng, het jaar voordien een scheepsaandeel van een achtste in zulk een vaartuig verworven

16. De hoogste ladingen, ingenomen door deze 21 vaartuigen, bedroegen 63 «chaldrons» (in 1 geval), 54 (in 1), 50 (in 2), 48 (in 4), 47 (in 1), 46 (in 3), 45 (in 1), 42 (in 2), 40 (in 2), 36 (in 1), 34 (in 2) en 24 (in 1). Het gemiddelde daarvan is ongeveer 43 "chaldrons». We veronderstellen dan ook dat een schip met een lading van 34 of 36 «chaldrons» er evengoed zowat 40 zou hebben kunnen inladen en dat dit dan zijn draagvermogen kan geweest zijn.

17. Bijlage, items 162 en 164,118 en 192, 62, 46 en 196. 
had ${ }^{18}$. Dit wijst er wellicht op, dat er zich onder de Vlaamse kolenschepen eenheden van het type ever, boeier of hulk, althans van kleine omvang, moeten bevonden hebben, wat zeker voor de vloot van Sluis en ook die van Duinkerke niet uit te sluiten is ${ }^{19}$. Verder mogen we aanvaarden, dat daarnaast een groot aantal vissersvaartuigen van allerhande grootte en type, waaronder ook korvers, aan de kolentrafiek vanuit Newcastle deelgenomen hadden. Opvallend in ieder geval in dat opzicht is het aandeel van de eenheden van de kleine aanleg- of vissersplaatsen Lombardsijde, Walravensijde, Nieuwerhaven en vooral Heist, zodat we ons zouden mogen afvragen voor wiens rekening hun stuurlui de ingeladen steenkool vervoerd hadden, waarbij we dan onmiddellijk denken aan Brugge met de Zwinhavens, draaischijven van de hanzeatische handelsscheepvaart ${ }^{20}$.

Van de 84 hier besproken Vlaamse vaartuigen wordt in de rekening van 1377-1378 telkens niet alleen de plaats van herkomst, maar ook de naam van het schip zelf en van diens stuurman vernoemd, alhoewel steeds in Engelse spelling met fonetische inslag. Niet minder dan $3 \nmid$ onder deze eenheden, waarvan 13 uit Nieuwpoort en 8 uit Heist, droegen de naam «Maryschippe». Daarnaast waren er 10, die «Crucebergh», d.i. «Kruisberg», 7 die «Blitheleme», d.i. «Blijdeleven», 7, die «Godewille», d.i. «Godswil», 5, die «Cristofor», 2, die «Katherine» en 2, die «Laurence»

18. «... ghecalengiert een achtendeel van eenen eeuerkine, $t$ welke toe behoorde Colin Spronghe, die bastaerd was, die staerf buten lande, $t$ welke de bailliu... vercocht heift Boudin Hallinghe van der Nieuwerpoort ende heift der of ontfaen 24 lb.». Brussel, Alg. Rijksarch., Rekenkamer van Vlaanderen en Brabant, nr. 1502 (of 1503, dubbel), rekening van Jan Lennoot, waterbaljuw van het Zwin, over de periode 11 mei - 21 sept. 1377. - Bijlage I, items 117 en 172.

19. R. DEGRYSE, De Vlaamse westvaart en de Engelse represailles omstreeks 1378 , in Hand. der Maatsch. voor Gesch. en Oudheidkunde te Gent, Nieuwe Reeks, dl. XXVII, 1973, p. 193-239. Zie p. 201-202, 211 en 218, bijlage II.

20. «Dou royaume d Angleterre viennent lainnes, cuir, plons, estains, charbon de roche, fromaige». L. GILLIODTS-VAN SEVEREN, Cartulaire de l'ancienne estaple de Bruges, dl. I, Brugge, 1904, p. 19, nr. 14. Document van omstreeks 1300, getiteld $« \mathrm{C}$ est li roiaume et les terres, desquez les marchandises viennent a Bruges et en la terre de Flandres». Niet gedateerd, maar daar in het stuk ook de Deense haring, d.i. Schonense kaakharing, vernoemd wordt, waarvan de stapel in 1324 te Damme gevestigd geworden was, mogen we aanvaarden dat de tekst van na die datum moet dagtekenen. 
of «Laurentius» heetten ${ }^{21}$. De overige 14 schepen hadden elk eveneens een naam, die hetzij met een patroonheilige, hetzij met de eredienst, hetzij met de verpersoonlijking van het vaartuig te maken had, namelijk «Boye», «Doubeler», «Godtyde», «Hauler», «Juliane», «Lightfote», «Lodewyk», «Margaret», «Maudeleyn», «Nicholas», «Palmer», «Victor», «Winpeny» en «Wonder». Niet al deze namen in een Engels kleedje zijn even gemakkelijk tot de Middelnederlandse originele term te herleiden. Waarschijnlijk slaat de benaming «Boye» op een boeier of klein vrachtschip en de naam «Lightfote» op «Lichtvoet» of een licht, snelvarend vaartuig. Met «Doubeler» of "Dobbelaar» en "Winpeny» of "Winpenning» belanden we, langs het taaleigen, in de typische wereld zelf van de gokkende en avontuurlijke zeelui, voor wie het schip zoveel als de belichaming van hun streven was ${ }^{22}$. Gezien het groot aantal Vlaamse vaartuigen, dat we aldus gedurende de periode oktober 1377 - september 1378 leren kennen, mogen we ons wellicht afvragen of we, althans in het geval van de vloten van Duinkerke, Nieuwpoort, Lombardsijde, Heist en Sluis, niet staan voor het gros van de Engelandvaarders van die plaatsen ${ }^{23}$. Wat er ook van zij, de genoemde rekening van de "custom» te Newcastle is stellig niet zonder belang voor de maritieme geschiedenis van Vlaanderen, evenals voor die van Zeeland, Holland en de Duitse hanzesteden. Tijdens de betrokken periode waren inderdaad ook nog 2770 «chaldrons» steenkool in 55 ladingen door 50 schepen, herkomstig uit 20 Zeeuwse, Hollandse en hanzische havens, vanuit Newcastle geëxporteerd geworden. Van deze vaartuigen hadden er zowat 27 aldaar ook goederen gelost, vooraleer kolen in te laden. Daarnaast

21. In die tijd waren er te Nieuwpoort twee parochiale kerken, waarvan de ene aan O.-L.-Vrouw en de andere aan Sint-Laurentius toegewijd.

22. G. ASAERT, Westeuropese scheepvaart in de middeleeuwen. Bussem, 1974, p. 64, 79 en 101-113, over de boeier en andere middeleeuwse scheepstypes, benevens p. 125-132, over de zeelieden.

23. Ter vergelijking: gedurende het boekjaar 1378-1379 bedroeg te Great Yarmouth het aantal bezoeken van vaartuigen uit Sluis twaalf en van eenheden uit Heist negen. H.J. SMIT, Bronnen tot de geschiedenis van den handel met Engeland, Schotland en Ierland, dl. I, vol. 1 (rijks Geschiedkundige Publikatiën, nr. 65), 's Gravenhage, 1928, p. 316-327, nr. 576. - Norwich. Norfolk and Norwich R.O., Arch. of Great Yarmouth, Borough Court Rolls, nr. 90, m. 8-11. 
waren te Newcastle nog 28 eenheden uit genoemde havens aangekomen om er koopwaren te lossen en daarna, zonder steenkolen ingeladen te hebben, te vertrekken, wat het totaal aantal schepen uit Zeeland, Holland en de hanzesteden, die gedurende de besproken periode aldaar gemeerd hadden, op 78 brengt. Onder de goederen, die ze aangevoerd hadden, vinden we o.m. "cokaille» d.i. keukengerei, zout, hout, "osemond» of Zweeds ijzer, ander ijzer, linnen, teer, tegels en ook kaakharing uit Schonen. Meerdere vaartuigen, die dergelijke waren te Newcastle gelost en daarna steenkool ingescheept hadden, vertrokken zelfs met een gunstige handelsbalans ${ }^{24}$. Dit alles zou er kunnen op wijzen, wat eigenlijk voor de hand ligt, dat te Newcastle de uitvoer van deze brandstof meer en meer de import van allerlei goederen in de hand werkte en dat dit minder de Vlamingen dan de Noordnederlanders en de hanzeaten ten goede kwam. Indien tijdens het genoemde jaar 13771378 de Vlamingen aldaar in de export van de steenkool toch nog zowat $64 \%$ ervan op hun aktief hadden, dan was dat ongetwijfeld te danken aan het verdrag van goede verstandhouding, dat door Lodewijk van Male, graaf van Vlaanderen, op 28 september 1377 met Richard II, de nieuwe koning van Engeland, gesloten geworden was en op de verlenging van de tussen de beide landen vroeger aangegane akkoorden neerkwam ${ }^{25}$. De Honderdjarige Oorlog tussen de Franse en Engelse vorstenhuizen was toen inderdaad, na een rustpoos, terug in gang gekomen ${ }^{26}$.

De rekeningen van de «customs" te Newcastle over de boekjaren 1378-1379 en 1379-1380 bleven niet bewaard, zodat we de omvang van de kolenexport aldaar door vreemde schepen gedurende die beide periodes en het Vlaams aandeel daarin niet kunnen nagaan. Wel mogen we veronderstellen dat toen, onder invloed van de gespannen internationale toestand en de daarmee gepaard gaande represailles en kaapvaart, genoemde kolenuitvoer begon af te nemen. Zeker is dat in 1379 de kolenschepen vertrekkend uit New-

24. BLAKE, p. 17-18. - Londen, P.R.O., Customs account E 122/106/1.

25. Th. RYMER, Foedera, conventiones, litterae inter reges Angliae et alios quosvis reges etc., 's Gravenhage, 1739-1745, dl. III, vol. 3, p. 70.

26. Ch. DE LA RONCIÈRE, Histoire de la marine française, dl. I, Parijs, 1909 , p. 51-63, chap. IV : «campagnes navales de 1377 à 1380». 
castle, evenals de haringschepen en andere vissersboten, benevens de koopvaardijschepen, varende voor de Engelse oostkust, door de Engelsen onder de bescherming van enkele bewapende konvooiers gesteld dienden te worden ${ }^{27}$. Zoals blijkt uit de rekening van de «custom» te Newcastle over het boekjaar eind september 1380 eind september 1381, was de export van steenkolen aldaar toen nog aanzienlijk, alhoewel het aandeel van de Vlamingen daarin fel verminderd te voorschijn $\mathrm{kwam}^{28}$. De totale uitvoer over zee van kolen aldaar bedroeg er zowat 5356 "chaldrons» in 117 scheepsladingen. Het aandeel van de Vlaamse schepen in deze hoeveelheid bereikte slechts 991 "chaldrons" in 22 ladingen, verdeeld als volgt $\mathrm{t}^{29}$ :

$\begin{array}{lrrr}\text { Duinkerke } & 1 & 1 & 40 \\ \text { Nieuwpoort } & 3 & 5 & 189 \\ \text { Nieuwe IJde } & 1 & 2 & 80 \\ \text { Lombardsijde } & 5 & 5 & 232 \\ \text { Oostende } & 1 & 1 & 28 \\ \text { Heist } & 1 & 1 & 60 \\ \text { Sluis } & 4 & 4 & 260 \\ \text { Biervliet } & 1 & 1 & 40 \\ \text { Nieuwerhaven } & 2 & 2 & 62 \\ \text { Totaal } & 19 & 22 & 991\end{array}$

27. SALZMAN, p. 271. - Londen, P.R.O., Rot. parl., dl. iii, 63 : twee «niefs», twee «bargis» en twee «ballengers» werden toen als konvooiers ingezet.

28. BLAKE, p. 18-19.

29. London, P.R.O., Custom account E 122/106/4, items 5, 36, 37, 38, 53, 65, $69,75,88,89,90,91,92,97,110,112,113,115,116,120,131$ en 143. 
Naast de 19 Vlaamse schepen, die te Newcastle steenkolen ingeslagen hadden, somt de betrokken rekening er nog 6 andere op, die er waren komen aanleggen om er goederen te lossen, namelijk 2 uit Duinkerke, 1 uit Heist, 1 uit Sluis, 1 uit Nieuwerhaven en 1 uit Hugevliete. Laatst genoemd vaartuig had er 25 last Schonense kaakharing aangevoerd ${ }^{30}$. Onder de Vlaamse kolenschepen bevonden er zich eveneens enkele, die te Newcastle koopwaren gelost hadden, vooraleer steenkool in te laden. Zo had een schip uit Lombardsijde er, naast drie tonnen olie, niet minder dan 9000 tegels afgeleverd en een vaartuig uit Nieuwpoort 1000 schapenvachten ${ }^{31}$. Voor het overige bestonden de weinige door de Vlamingen te Newcastle geloste goederen uit bier, olie, fruit, noten, knoflook, zout, lampreien of prik, kurk, ijzer, metalen kruiken en ledige tonnen. Naast steenkolen, waren door enkele Vlaamse vaartuigen ook molenstenen, mostaard- en uienzaad uitgevoerd geworden ${ }^{32}$. Van de 25 eenheden, die aldus aan deze trafiek deelgenomen hadden, droegen er zes de naam «Godewylle» en vijf de naam «Seint Maryshippe». Twee heetten «Crucemberghe», twee «Godbered» d.i. "Godsberaad», en de overige tien respectievelijk «Nicholas», «Maryknight», «Palmer», «Seint Jameshippe», «Goderest», «Maister Jone», «Andreyus», «Blythelevyn», «Seint Joneshippe» en «Comweltohous» d.i. «Komwelthuis». Van de 19 kolenschepen waren er 7 met een lading of draagvermogen van minder dan 40 «chaldrons», 9 met een variërend van 40 tot 60 «chaldrons" en 3 met een van meer dan 60 "chaldrons», namelijk een eenheid uit Lombardsijde, geladen met 80 "chaldrons», en twee uit Sluis, respectievelijk geladen met 70 en 80 «chaldrons», dus vaartuigen van 35 à 40 last $^{33}$.

Op te merken is, dat van de besproken Vlaamse vaartuigen, vier,

30. Ib., items 16, 24, 48, 49, 50 en 59. - Voor het vaartuig uit Hugevliete zie item 57.

31. Ib., items 36 en 97.

32. Ib., items 36, 38, 53, 89 en 90 .

33. Een vaartuig uit Nieuwpoort had achtereenvolgens drie ladingen steenkool ingeslagen en een uit de Nieuwe IJde twee. Ib., items 37 (38 «chaldrons»), 88 (40 ch.) en 120 ( $31 \mathrm{ch}$.$) en items 91$ (40 ch.) en 112 (40 ch.). - Voor de twee grote eenheden uit Sluis zie items 5 en 36 en voor de grote eenheid uit Lombardsijde item 65 . 
respectievelijk herkomstig uit Duinkerke, Lombardsijde, Heist en Nieuwerhaven, met dezelfde schipper ook in 1378 Newcastle aangedaan hadden om er steenkolen in te laden en uit te voeren ${ }^{34}$. Daarnaast waren er nog drie andere stuurlui, beurtelings herkomstig uit Duinkerke, Heist en Sluis, die dat jaar aldaar eveneens kolen ingescheept hadden, maar dan in een ander schip, dan dit waarover ze in 1381 het gezag hadden ${ }^{35}$. Dit wijst ongetwijfeld op een zekere continuiteit in de Vlaamse kolenexport vanuit Newcastle. Voor het overige zien we tijdens het boekjaar 1380-1381 in het totaal 4365 «chaldrons» steenkolen in 95 ladingen door 84 schepen uit Zeeland, Holland en het hanzegebied te Newcastle uitgevoerd worden ${ }^{36}$. Vergeleken met hun aandeel in de kolenuitvoer gedurende het boekjaar 1377-1378, waren de Zeeuwen, Hollanders en hanzeaten er dus goed op vooruitgegaan, wat blijkbaar door de achteruitgang van de Vlamingen op dat gebied te verklaren is.

Aansluitend bij de rekening van de «custom» op de export van steenkool te Newcastle van eind september 1380 - eind september 1381 is die over de tweejarenperiode eind september 1381 - eind september 1383, waarvan het exemplaar eveneens bewaard bleef. Voor het onderzoek van de Vlaamse kolentrafiek is echter alleen het gedeelte van deze rekening over het boekjaar eind september 1381 - eind september 1382 van belang, daar het jaar nadien, gedurende dezelfde tijdspanne van twaalf maanden de Vlamingen, met uitzondering van een schip uit Nieuwerhaven, Newcastle niet aandeden ${ }^{37}$. Op een totaal van 4906 chaldrons steenkool, die tijdens het boekjaar 1381-1382 in zowat 110 scheepsladingen aldaar

34. Ib., items 49 (D), $59(\mathrm{H}), 89$ (L) en $143(\mathrm{NH})$. - Zie in de bijlage items 111 en 179 (D), 85, 105 en $138(\mathrm{H}), 47$ en 120 (L) en 18 en $19(\mathrm{NH})$.

35. E 122/106/4, items 65 (S), 113 (D) en $131(\mathrm{H})$. - Zie in de bijlage items 150 (S), 149 (D) en 1 (H).

36. BLAKE, p. 18-19. - SMIT, dl. I, vol. 1., p. 336-342, nr. 589, lijst van de Noordnederlandse vaartuigen, die tijdens het boekjaar 1380-1381, Newcastle aangedaan hadden. Ontleding van de rekening van de «custom» aldaar.

37. London, P.R.O., E 122/106/5. Het perkament is hier en daar beschadigd. BLAKE, p. 19-20, ontleding van de rekening over de tijdspanne 29 sept. 1381 - 29 sept. 1382. Het daaropvolgend gedeelte over de periode 29 sept. $1382-29$ sept. 1383 wordt door Blake buiten beschouwing gelaten, alhoewel in de zowat 100 items ervan de uitvoer van steenkool door Zeeuwse, Hollandse en hanzeatische schepen opgesomd wordt. 
uit de haven weggevoerd werden, was er een hoeveelheid van 1520 «chaldrons» op rekening van de Vlaamse vaartuigen, te verdelen als volgt :

\begin{tabular}{|c|c|c|c|}
\hline Duinkerke & 7 & 8 & 362 \\
\hline Nieuwpoort & 3 & 4 & 150 \\
\hline de Nieuwe IJde ${ }^{38}$ & 1 & 1 & 40 \\
\hline Lombardsijde $^{38}$ & 1 (of 2 ) & 2 & 178 \\
\hline Walravensijde ${ }^{38}$ & 3 (of 4) & 6 & 265 \\
\hline Oostende & 1 & 1 & 48 \\
\hline Sluis & 9 & 9 & 481 \\
\hline Nieuwerhaven & 1 & 1 & 36 \\
\hline Totaal & 26 (of 28 ) & 32 & 1560 \\
\hline
\end{tabular}

Gedurende het hier besproken boekjaar hadden nog acht andere Vlaamse vaartuigen Newcastle aangedaan om er koopwaren te lossen en daarna zonder een lading steenkool de haven te verlaten. Het waren meer bepaald een eenheid uit Duinkerke, een uit Nieuwpoort, een uit Hugevliete, twee schepen uit Sluis en drie uit Nieuwerhaven ${ }^{39}$. Aldus komen we tot een totaal van ongeveer 35 Vlaamse vaartuigen, die tijdens het boekjaar 1381-1382 Newcastle binnengevaren waren. Het grootste aantal onder hen, namelijk 21, had er, vooraleer met of zonder een lading kolen te vertrekken,

38. De desbetreffende items zijn ten dele onleesbaar. In item 34 staat «Neuhywe» of "Neuhywt» blijkbaar voor de Nieuwe IJde.

39. Ib., items 37 (D), 142 (N), 80 (H), 93 en 115 (S), 24, 27 en 29 (NH). De rekening vermeldt ook vier Vlaamse schepen die elk met een lading wol en huiden vertrokken waren. 
een vracht goederen gelost ${ }^{40}$. Onder de geloste koopwaar vinden we vooral tegels, zout en appelen en daarnaast ook aardewerk, keukengerei, houten balken, ijzer, meekrap, linnen, uien, zalm, vet en zelfs ezels. Van de genoemde 35 eenheden, die aan de trafiek op Newcastle deelgenomen hadden, waren er vijftien met de naam «Seint Maryshippe» en een met de naam «Seint Maryknyght». Vier heetten "Crucemberghe», vier "Christofore», drie "Comeweletohous» en de overige acht respectievelijk «Blythleven", «Flour de Lies», «Godesknyght», «Goderoste», «Godewylle», «Johannes», «Lychtfote» en «Pasedaughe», benamingen die ongetwijfeld duidelijk genoeg zijn. De ingeslagen ladingen steenkool varieerden van 24 tot 90 «chaldrons». Van de 26 of meer bij de verscheping daarvan betrokken vaartuigen waren er een vijftal met een laadvermogen van ten hoogste 40 «chaldrons», achttien met een laadvermogen van 40 tot 60 "chaldrons» en drie met een laadvermogen van meer dan 60 "chaldrons» ${ }^{41}$. De twee grootste eenheden kwamen uit Sluis en Lombardsijde en hadden elk een kapaciteit van 90 «chaldrons». Een van hen, de «Seint Maryshippe» uit dit laatste stadje was een eerste maal, in april 1382, met een lading steenkool, bedragende 88 «chaldrons», uit Newcastle vertrokken en een tweede maal, op 22 juli van dat jaar, met een vracht bedragende 90 «chaldrons». De «Seint Maryshippe» uit Sluis had maar één maal Newcastle aangedaan om er 90 "chaldrons" kolen in te laden. Een ander vaartuig uit deze Zwinhaven, eveneens «Maryshippe» geheten, had er 70 «chaldrons» ingeno$\operatorname{men}^{42}$. Deze drie eenheden waren blijkbaar groter dan de gewone haringschepen of vissersboten, die ten hoogste een tonnenmaat van

40. Ib., items $1,4,5,18,24,27,29,31,34,35,37,42,43,44,68,70,80,93$, $107,113,115$ en 142 . Items 4 en 31 betreffen een en hetzelfde vaartuig uit Nieuwpoort.

41. Drie vaartuigen hadden elk achtereenvolgens tweemaal Newcastle aangedaan en steenkool ingeladen. Ib., items 54 ( 50 ch.) en 86 (60 ch.) voor Duinkerke ; 4 (36 ch.) en 31 ( $36 \mathrm{ch}$.) voor Nieuwpoort ; 121 (50 ch.) en 146 (50 ch.) voor Walravensijde. Een tweede eenheid uit dit laatste plaatsje had driemaal te Newcastle kolen ingeladen. Ib., items 43 (45 ch.), 113 (40 ch.) en 147 (40 ch.).

42. Ib., items 42 en 134 (L), 135 en 145 (S). 
30 last of zowat 60 «chaldrons» hadden ${ }^{43}$. Naast de 1560 «chaldrons» steenkool door de Vlaamse vaartuigen uitgevoerd, waren vanuit Newcastle de overige 3346 «chaldrons» door Zeeuwse, Hollandse en hanseatische schepen geëxporteerd geworden en dit in ongeveer 80 scheepsladingen. Voor al de kolenvrachten samen kwam dit per schip neer op een gemiddelde lading van zowat 45 «chaldrons» ${ }^{4}$.

De stilstand, die we in 1383 in de uitvoer van steenkool te Newcastle door de Vlamingen vaststellen, was ongetwijfeld aan de toenmalige beroerde toestand in Vlaanderen zelf te wijten, namelijk de opstand van Gent onder leiding van Filips van Artevelde en, als gevolg daarvan, de Franse tussenkomst. Zelfs na de nederlaag van de Gentenaars in de slag bij Westrozebeke op 27 november $138 \not 22$ kwam er nog geen onderwerping aan het gezag van graaf Lodewijk van Male, die in 1384 stierf en door zijn schoonzoon, Filips de Stoute, hertog van Bourgondië, opgevolgd werd. Eerst in 1385 kon deze laatste met de Gentenaars, die tot dan toe de steun van

43. In 1319 of een of meerdere jaren daar vóór verloor stuurman Claiman Michiel uit Oostende «een schip ende t ghewant ende 22 last harinx ende 1300 cabeliaus benorden Jernemude up die wilde ze» als gevolg van een kaping door zeeroves uit genoemde haven : Great Yarmouth. Gent, Rijksarch., fonds de Saint Genois, nr. 1373, rol getiteld «nouvielles complaintes des Flamens contre les Engles», item 3. - In de vrijgeleiden door de Engelse koningen aan de vissers uitgereikt werd soms bepaald dat hun vaartuigen ten hoogste een draagvermogen van 30 last per eenheid hebben mochten. Aldus in 1460 ten voordele van een visserstuurman uit Dieppe : "Rex... dedimus et concessimus... bonum securum verumque salvum conductum, die prima mensis junii proximo nunc venturi, per unum annum integrum ... Johanni Vinet, magistro unius batelle seu vasis ad piscendum ordinati portagii triginta doliorum vel infra, de parte nobis adversa...»M. MOLLAT, La pêche à Dieppe au XVe siècle, in Bull. de la Soc. libre d'Emul. du commerce et de l'industrie de la Seine-Inférieure. Exercice 1938, Rouen, 1939, p. 169-210. Zie p. 206, pièce 2. Stuk van 20 mei 1460. - London, P.R.O., Treaty Rolls 142, m. 10, 30 Henry VI. - Voor de 14de eeuw, zie J. NOËL DE LA MORNIÈRE, Histoire générale des pêches anciennes et modernes. Parijs, 1815, p. 315, zonder bronvermelding.

44. Blake, 19-20. - Bij de Vlaamse vaartuigen is gebeurlijk nog te voegen een schip uit «Burge», plaats, die door Blake met Brugge geïdentificeerd wordt. Het heette Seint Maryschip en het had «64 chaldrons» steenkool ingeslagen. Met «Burge» moet misschien eerder Burg in Zeeland bedoeld geweest zijn. Genoemde rekening, boekjaar 1381-1382, item 76, datum van vertrek : 2 juni 1382. 
de Engelse koning Richard II genoten hadden, de vrede sluiten ${ }^{45}$. Of toen onmiddellijk de Vlaamse trafiek op Newcastle terug plaats vond, is te betwijfelen, gezien het Frans-Bourgondisch familiaal verbond en de mislukte Franse expedities tegen Engeland in 1386 en 1387. Wellicht mogen we aanvaarden, dat dit eerst daarna gebeurde, wat zou kunnen blijken uit de vierde hier besproken rekening van de kleine "custom" te Newcastle, meer bepaald die over de periode gaande van 29 september 1390 tot 8 december 1391 . Gedurende deze tijdspanne van nagenoeg veertien maanden bedroeg de totale uitvoer over zee van steenkool te Newcastle zowat 5000 «chaldrons», in ongeveer 118 scheepsladingen, waarvan 16 met in het geheel 620 «chaldrons» in Vlaamse vaartuigen. De overige vrachten van die aard waren in Engelse, Franse, Zeeuwse, Hollandse en hanzeatische eenheden verscheept geworden ${ }^{46}$. Slechts een vijftal Vlaamse havens hadden aan deze trafiek deelgenomen en hun aandeel erin was als volgt:

$\begin{array}{lrr}\text { Haven of ijde van } & \text { werkelijk aantal } & \text { aantal ladingen } \\ \text { herkomst van het schip } & \text { deelnemende schepen } & \text { steenkool heelheid }\end{array}$

$\begin{array}{lrrr}\text { Nieuwpoort } & 5 & 5 & 227 \\ \text { Oostende } & 1 & 1 & 20 \\ \text { Heist } & 2 & 2 & 90 \\ \text { Sluis } & 6 & 7 & 249 \\ \text { Nieuwerhaven } & 1 & 1 & 34 \\ \text { Totaal } & 15 & 16 & 620\end{array}$

45. W. PREVENIER, Les perturbations dans les relations commerciales angloflamandes entre 1379 et 1407. Causes de désaccord et raisons d'une réconciliation, in Publications de la Sorbonne, série Etudes, dl. V. Economies et sociétés du Moyen Age, Mélanges Edouard Perroy, Parijs, 1973. Overdruk in Studia Historica Gandensia nr. 182. Gent. 1973.

46. London, P.R.O., Custom account E 122/106/21. - Ontleding en bespreking in grote lijnen in J.B. BLAKE, p. 20-21. Daarbij heeft deze auteur, naar we vermoeden, ook gesteund op de rekening E 122/106/22, althans voor wat enkele Engelse en andere schepen aangaat. Zie ibidem, p. 16, n. 102. 
Naast de 15 geciteerde kolenschepen, vinden we in de rekeningen nog 6 andere Vlaamse vaartuigen, die eveneens Newcastle aangedaan hadden, vermeld. Het waren meer bepaald 4 eenheden uit Sluis en 2 uit Nieuwerhaven, die aldaar goederen gelost hadden en nadien zonder een lading steenkool vertrokken waren ${ }^{47}$. Van de 21 Vlaamse schepen, die aldus in de rekening opgesomd worden, waren er in het totaal 11, die te Newcastle een vracht koopwaren gelost hadden, namelijk 7 uit Sluis, 3 uit Nieuwerhaven en 1 uit Heist ${ }^{48}$. Onder de aangevoerde goederen vinden we vooral zout, wede, vet, ijzer, laken, linnen, meekrap, aluin, was, hennep en lamprei. Een vaartuig uit Sluis had niet minder dan 12000 tegels ontladen $^{49}$. Van de genoemde Vlaamse vaartuigen waren zes genaamd «Maryschip», drie "Marieknyght», twee «Godewyle», twee «Katrina» en een «Ardore», «Comeweltohous», «Christofer», «Crucemberghe», «Haligast», "Maidaugh», «Plukrose» of "Seint Maribote». Laatste naam is zeker als dusdanig relevant, aangezien hij duidelijk op een boot en niet op een schip sloeg. Desbetreffend vaartuig was uit Sluis herkomstig en had een lading van slechts 12 "chaldrons" steenkool ingescheept ${ }^{50}$. Dit was de kleinste van de door Vlaamse eenheden te Newcastle ingeslagen vrachten kolen. Acht andere onder deze schepen moeten elk een laadkapaciteit tot 40 «chaldrons» gehad hebben. Een schip had een lading van 44 «chaldrons» ingedaan ${ }^{51}$. Daarentegen waren er vier eenheden met

47. E $122 / 106 / 21$, items $4,5,6$ en 46 voor Sluis en 44 en 45 voor Nieuwerhaven.

48. Ib., items 1, 4, 5, 6, 9, 46 en 48 voor Sluis, 39 voor Heist, 31, 44 en 45 voor Nieuwerhaven.

49. Ib., item 48.

50. Ib., item 171. - In de 16de eeuw maakten de Oostendse vissers een onderscheid tussen schepen en boten, blijkbaar naar gelang de grootte van de betrokken eenheden. Reeds in het begin van de 14de eeuw hadden ze dit gedaan voor de vaartuigen van het type «makereelschip» en "makereelboet». R. DEGRYSE, Van "buza» tot «buis», de ontwikkeling van het Vlaamse vissersvaartuig (12de - 16de eeuw), in Ostendiana, dl. I, Oostende, 1972, p. 137-158. Zie p. 142, n. 21, en p. 152, n. 63. - Daaruit zouden we kunnen afleiden, dat met een vaartuig, geheten "Maryship», steeds een schip bedoeld werd.

51. E 122/106/21, items 15, 103, 112, 132, 133, 137, 144, 145 en 159. Eén vaartuig had na elkaar twee maal een lading steenkolen ingenomen, telkens 30 «chaldrons», zie items 15 en 145 . Voor de eenheid van de grootte van 44 of meer «chaldrons», zie item 120. 
een vracht van 60 "chaldrons" en een met een lading van 62 «chaldrons». Van deze grotere vaartuigen kwamen er twee uit Sluis, twee uit Nieuwpoort en een uit Heist ${ }^{52}$.

De gegevens over de Vlaamse kolenschepen te Newcastle, die we in de rekeningen van de heffing van de kleine "custom» aldaar over de boekjaren 1380-1381, 1381-1382 en 1390-1391 aantreffen, stroken met die voorkomende in de rekening over het boekjaar 13771378. Vooral tijdens de maanden juni, juli en augustus werd door de Vlamingen aan kolentransport over zee vanuit Newcastle gedaan en dit kennelijk meestal met vissersschepen vóór het haringseizoen in de zuidelijke Noordzee. De genoemde rekeningen verschaffen ons aldus enkele bijzonderheden over een minder bekend aspekt van de Vlaamse vrachtvaart en aktieve handel op de havens van de Engelse oostkust en over de rol daarin gespeeld door de vloten van Duinkerke, Nieuwpoort en Sluis, evenals door de vaartuigen uit Lombardsijde, Walravensijde, Oostende, Nieuwerhaven en Heist. Overigens is het aandeel van laatstgenoemde plaatsen in het vervoer van steenkool te verklaren door hun ligging nabij een haven, waarvoor ze aan scheepvaadrt deden en waarvan ze dus ten dele afgingen. Dat was zo voor Lombardsijde en Walravensijde ten overstaan van Nieuwpoort en voor Oostende, Heist, Nieuwerhaven en Biervliet ten overstaan van Sluis ${ }^{53}$. Opvallend is verder de afwezigheid van vaartuigen uit Blankenberge en Wenduine te Newcastle en dit zelfs tijdens het topjaar 1378. Althans voor de Blankenbergse schepen, die voor het overige wel aan de trafiek op Oost-Engeland deelnamen, kan dit verstek toen zuiver toevallig geweest zijn. Na dit alles blijft nog de open vraag: door wie

52. Ib., items 11 en $121(\mathrm{~S}), 139$ en $146(\mathrm{~N})$ en $60(\mathrm{H})$.

53. Typisch in dat opzicht is de aanvoer in 1378 te Newcastle door een vaartuig uit Heist van zes bootmasten. Deze waren ongetwijfeld te Sluis, waar dit scheepstuig toen te verkrijgen was, ingeladen geworden. Bijlage I, item 61 - Inderdaad in 1440 zien we twee burgers van Sluis betaald worden voor de levering van de grote mast en de twee andere masten, dienende voor de optuiging van de grote hertogelijke "nave», toen liggende in die havenstad R. DEGRYSE, De Bourgondische expedities naar Rhodos, Constantinopel en Ceuta, 1441-1465, in Mededelingen v.d. Mar. Ac., boek XVII, Antwerpen, 1965, p. 227-252. Zie p. 229 en 246, bijlage I. - Blijkbaar was de invoer van masten te Sluis een aktiviteit van de hanzeaten. 
allemaal, Engelse, Vlaamse, Zeeuwse, Hollandse, hanzeatische of Franse kooplui, waren de onderscheiden kolenschepen te Newcastle gecharterd geworden om steenkool naar een of andere Britse of vastelandshaven uit te voeren? Wat er ook van zij, een van de voornaamste plaatsen van bestemming was, buiten Londen, ongetwijfeld Sluis, de voorhaven van Damme en Brugge ${ }^{54}$.

J.B. Blake in zijn artikel heeft het alleen over de kolenexport per schip uit Newcastle en niet over de import aldaar in de haven van goederen komende van elders. Onder deze koopwaar bevond zich ook Schonense kaakharing, die er vooral tijdens het najaar of de maanden oktober, november en december uit Schonen, de zuidelijke punt van Zweden, toen aan Denemarken, ingevoerd werd. Het waren vooral de hanzeaten van de Noordduitse en Zuiderzeehavens, die zich met de handel in Schonense tonharing bezighielden. Na 1368 zien we evenwel ook de lieden van Amsterdam, Brielle, Zierikzee en andere Hollandse en Zeeuwse havens zich daarmee inlaten. Kennelijk trok deze trafiek weldra ook Vlaamse haventjes als Nieuwerhaven, Hugevliete en Biervliet, gelegen aan de Honte, aan, vermits juist daar in de Scheldedelta op het einde van de 14de eeuw de vissers tot het kaken op zee van de vóór de Engelse oostkust gevangen Noordzeeharing voor het eerst zouden overgaan ${ }^{55}$. Het belang van de rekeningen van de kleine «custom» te Newcastle voor het onderzoek van deze evolutie ligt dan ook voor de hand. Zo zien we in het najaar van 1377 in deze haven in het totaal \pm 150 last kaakharing uit Schonen ingevoerd worden, waaronder wel 80 last door twee schepen uit Brielle en 40 1 12 last door een vaartuig uit Zierikzee ${ }^{56}$. In 1380 gedurende dezelfde pe-

54. Zie n. 20.

55. R. DEGRYSE, Oorsprong van het haringkaken in Vlaanderen, in Nederlandsche Historiebladen, jg. I, nr. 2, Antwerpen, 1938, p. 201-219. Zie p. 206 ID., Schonense en Vlaamse kaakharing in de I4de eeuw, in Bijdr. voor de Gesch. der Ned., dl. XII, 1957, p. 100-107. - R. DEGRYSE en O. MUS, De laatmiddeleeuwse haringvisserij, p. 100-102.

56. «Navis vocata le Cristofor de Sirice unde Johannes Ertsone est magister applicuit in portu predicto $8^{\circ}$ die Novembri anno supradicto. Per eodem magistro pro 40 lastis et dim. de allecis de Scone val. 103 lb. - 25 s. 9 d. (custom)». «London, P.R.O., Custom account E 122/106/1, item 24. Zie aldaar ook de items 25, $27,28,29,30$ en 31 onder de data 8 november en 18, 23 en 26 december 1377 . Zie de bijlage, littera B. 
riode waren het 152 last, waaronder 26 last door een schip uit Brielle en 40 last door een uit Zierikzee, maar ook 25 last door een vaartuig uit Hughevliete in Vlaanderen ${ }^{57}$. In 1382 waren het 101 last door drie schepen uit Zierikzee, benevens nog een kleine, niet aangeduide hoeveelheid door een eenheid uit Kampen en dit tegenover in het geheel geen het jaar voordien ${ }^{58}$. In 1390 ten slotte waren het maar 12 last en 9 tonnen door een drietal vaartuigen, namelijk 5 last in een schip uit Middelburg, 4 last in een uit Veere en 3 last 8 tonnen in een uit Danzig, terwijl er nog een ton door een eenheid uit Zierikzee gelost geworden was ${ }^{59}$. Dat het daarbij werkelijk telkenmale om gekaakte haring uit Schonen ging, blijkt uit de in de rekening over het boekjaar 1377-1378 daarvoor gebruikte terminologie, namelijk "allex album de Scone»60. Weliswaar vinden we in de drie volgende rekeningen alleen nog de uitdrukking "allex album» zonder de specificatie «de Scone», maar het is duidelijk dat daaronder telkens eveneens het "witte», in tonnen gezouten produkt van Deens-hanzeatische oorsprong verstaan dient te worden ${ }^{61}$. Overigens staat de Schonense kaakharing te Newcastle in een akte van 26 juli 1395 uitdrukkelijk vermeld en wel in verband met een onderzoek, dat toen bevolen werd, ten einde de ontduiking van de betaling van de «customs», drukkend op de invoerhandel ervan, na te gaan, misbruik waaraan zich de lieden van de hanzeatische havenstad aan de Zuiderzee, Kampen,

57. «Petrus Selle, magister navi vocate Godewylle de Houghflete applicuit $7^{\circ}$ die Decembri cum 25 lastis allecis albi val. $50 \mathrm{lb}$. Custom $15 \mathrm{~d} . »$. E 122/106/4, item 16. Zie aldaar verder de items $3,10,16,17,18,20,22$ en 40 onder de data 9 en 24 oktober, 7, 10, 11 en 12 december 1380,28 januari en 24 maart 1381.

58. E $122 / 106 / 5$, items onder de data 23 oktober, 16 en 18 november 1382 en 2 maart 1383.

59. «Navis vocata Christofer de Dans unde Jacobus Lenesone est magister applicuit 10 mo die Novembri. Per eodem pro 3 lastis et 8 barellis alleci albi val. 11 lb. - Inde custom 2 s. 9 d.» E 122/106/21, item 65. Zie aldaar ook de items 66, 67 en 68 .

60. R. DEGRYSE, Het schip en de zeevisserij te Dieppe in de 15 de eeuw, in Meded. v. d. Marine Ac., boek XXII, 1971-1972, p. 25-76. Zie p. 38-39. - DEZELFDE, De Vlaamse westvaart, p. 204-212.

61. De term «allec album» betekent dus niet verse haring, zoals verkeerdelijk staat in SMIT, Bronnen, dl. I, vol. 2, register van zaken, p. 1446, verbo "visch". - Op 4 nov. 1393 voerde een schip uit Zierikzee te Great Yarmouth niet minder dan 55 last 4 tonnen «allec de skone» aan. Ibidem, dl. I, vol. 1, nr. 736, p. 462, item 61. 
zich schuldig gemaakt zouden hebben. Tegelijk was toen ook soortgelijk onderzoek inzake de uitvoerhandel in steenkool in dezelfde Engelse stad bevolen geworden ${ }^{62}$. Vermits Kampen zich in de 14de eeuw in de handel in Schonense tonharing gespecialiseerd had, ligt het voor de hand dat minstens tot 1396 met de term «allec album» in Engeland in de in het Latijn gestelde bescheiden genoemd produkt bedoeld werd ${ }^{63}$. Op dat ogenblik reeds waren de vissers uit de Lage Landen en Oost-Engeland op een bescheiden schaal met het zouten en kaken van Noordzeeharing begonnen en wel eerst aan wal, zoals in Schonen, en vrij spoedig daarna op zee, wat een totale omkeer in het kaakharingbedrijf teweeg zou brengen. Deze ingrijpende verandering, die de opkomst van een eigen tonharingbedrijf in de Lage Landen voor gevolg had, zou zich echter eerst na 1400 manifesteren. Naderhand werd, meer bepaald in Vlaanderen, door de overlevering, het initiatief voor deze vernieuwing toegeschreven aan een legendarisch figuur, met name Willem Beukel, herkomstig van Hugevliete nabij Biervliet, maar waarvan het historisch bestaan, als visser en kaper, toch vaststaat ${ }^{64}$. Het is duidelijk dat tussen de aanvankelijke trafiek in Schonense tonharing, waaraan tot omstreeks 1400 door de zeelui van vissershavens als Brielle, Zierikzee en Hugevliete gedaan werd, en de daaropvolgende opkomst in Holland, Voorne, Zeeland en Vlaanderen van het kaken van de Noordzeeharing een verband moet bestaan hebben, dat op een overgang van het ene op het andere neerkwam met al de gevolgen van dien. De «item» over de komst te Newcastle op 7 december 1380 van dat ene Vlaamse schip uit Hugevliete met een lading van 25 last Schonense kaakharing vult dan ook, inzake de gegevens betreffende de oorsprong van het haringkaken in Vlaanderen, een lacune aan.

62. Ibidem, dl. I, vol. 1, nr. 731, p. 436, noot 1, naar Cal. Pat. Rolls, 13961399, p. 52.

63. J. NANNINGA-UITTERDIJK, De haringvangst van Kampen op Schonen in de 14 de eeuw, in Bijdr. tot de gesch. van Overijssel, uitgegeven door J. Nanninga-Uitterdijk en L. Van Hasselt, dl. XI, 2de serie, 1ste vol. Zwolle, 1896, blz. 291 en vlg.

64. R. DEGRYSE, Willem Beukel(s) van Hughevliet, in De Vlaamse Gids, jg. 38, afl. 7, juli 1954, p. 403-410. - DEZELFDE, Willem Beukel en het begin van het kaken. Een antwoord, in Bijdr. voor de Gesch. der Ned., dl. IV, 1960, p. 217-220, aantekening. 


\section{BIJLAGE}

Lijst van de Vlaamse vaartuigen, die gedurende de periode 6 oktober 1377 - 28 september 1378 te Newcastle upon Tyne aankwamen en uit die haven met een lading steenkool of soms ook nog met molenstenen vertrokken, naar de rekeningen van de ontvangers van de kleine en grote «custom» aldaar, respectievelijk Johannes de Bulkham en Johannes de Bisshopsdale, over de tijdspanne 18 september 1377 - 8 februari 1378, en Johannes de Bulkham en Johannes de Eghtone, over de tijdspanne 8 februari - 29 september 1378 , beide gesteld in het Latijn. In de hiernavolgende ontleding sommen we per Vlaams schip achtereenvolgens op de naam van de stuurman, de naam en de plaats van herkomst van het vaartuig, gebeurlijk de datum van aankomst (A.), de aard en de handelswaarde van de geloste goederen en de daarvoor gestorte tol, alsmede de datum van vertrek (V.), de hoeveelheden ingeladen steenkool, gemeten in «chaldrons» of chaudrons, benevens gebeurlijk andere koopwaar, de handelswaarde ervan en de tol, die ervoor betaald werd. De «items", zoals ze in de beide rekeningen op elkaar volgen, namelijk 38 in de eerste rekening en 162 in de tweede, of samen 200, hebben we van een nummer voorzien. Hieronder weerhouden we alleen wat op de vaartuigen uit Vlaanderen slaat en laten we de kolenschepen uit Zeeland, Holland en de hanzehavens buiten beschouwing. De namen van de stuurlui, schepen en thuishavens geven we in hun Engelse spelling, zoals ze in de rekeningen voorkomen. De opgesomde bedragen staan in ponden (lb.), schellingen (s.) en penningen (d.), benevens obolen (ob.) Engelse munt, d.i. sterling. In annex, onder littera B, lijst van de Noordnederlandse eenheden, die te Newcastle Schonense kaakharing ontladen hadden, opgesteld volgens dezelfde normen.

- Londen, Public Record Office, Custom account E 122/106/1

- Gedeeltelijke ontleding en bespreking in J.B. Blake, The medieval coal trade of North East England: some fourteenth-century evidence, in : Northern History. A review of the history of the North of England. The University of Leeds, vol. II, 1967, blz. 1-26), blz. 17-18.

5 - Willelmus Jacobsone - le Maryschippe de Neuhavene (Nieuwerhaven)

$\mathrm{V}-12$ oktober - 60 chaldrons (100 s.) - $15 \mathrm{~d}$.

8 - Jacobus Henrisone - le Maryschippe de Dunkirke (Duinkerke) A - 6 oktober 1377 - zout en andere goederen (108 s. 4 d.) - $16 \mathrm{~d}$.

V - 14 oktober - 38 chaldrons (63 s. 4 d.) - 9 d.ob.

9 - Michael Romelore - Lodewyk de Dunkirke V - 14 oktober - 60 chaldrons (100 s.) - $15 \mathrm{~d}$. 
10 - Petrus Heynman - le Maryschippe del Haijs (Heist) V - 16 oktober - 60 chaldrons (100 s.) - $15 \mathrm{~d}$.

11 - Johannes Corver - le Maryschippe del Scluys (Sluis) $\mathrm{V}-16$ oktober - 56 chaldrons (4 lb.13 s.4 d.) - $14 \mathrm{~d}$.

15 - Baudewyn Petrussone - le Cristofor del Scluys (zie nr. 23) A -8 oktober - handelswaar (100 s.) - $15 \mathrm{~d}$. $\mathrm{V}-16$ oktober - 54 chaldrons (4 lb.10 s.) - 13 d.ob.

16 - Johannes Hallyng - Seint Maryschippe del Scluys $\mathrm{V}-16$ oktober - 48 chaldrons (4 lb.) - $12 \mathrm{~s}$.

18 - Ivo Jonessone - le Godewille de Neuhaven V - 18 oktober - 24 chaldrons (40 s.) - $6 \mathrm{~d}$.

19 - Ivo Jonessone - le Godewille de Neuhaven V - 26 oktober - 24 chaldrons (40 s.) - $6 \mathrm{~d}$.

23 - Baudewyn Petrussone - le Cristofor del Scluys (zie nr 15) $V-20$ november - 39 chaldrons (60 s.) - 9 d.

33 - Johannes Halling - le Palmer de Neuport (Nieuwpoort) A -2 februari 1378 - zout, appelen en andere goederen (116 s. 8 d.) - 17 d.ob.

$V-7$ februari - 40 chaldrons en een molensteen ( 6 lb. 6 s. 8 d.) $19 \mathrm{~d}$.

34 - Michael Hane - le Maryschippe de Neuport

A -2 februari - appelen en andere goederen ( 56 s. 8 d.) - 8 d.ob.

$\mathrm{V}-7$ februari - 42 chaldrons (4 lb. $10 \mathrm{~s}$.) - 13 d.ob.

36 - Nicholaus Hane - le Laurence de Neuport

A -2 februari - appelen en tegels ( 23 s. 4 d.) - 3 d.ob.

V -7 februari - 26 chaldrons (43 s. 4 d.) - 6 d.ob.

38 - Christianus Deringsone - le Maryeschippe de Neuhavene

A -2 februari - linnen (4 lb. 10 s.) - 13 d.ob.

$\mathrm{V}-7$ februari - 56 chaldrons (100 s.) - $15 \mathrm{~d}$.

41 - Georgius Willelmussone - le Maryschippe del Haijs

V - 20 februari - 52 chaldrons (106 s. 8 d.) - 16 d.

46 - Johannes Ryner - le Marieschippe de Neuport (zie nr 131)

A -22 februari - appelen en andere goederen ( $23 \mathrm{~s} .8 \mathrm{~d}$.) -

3 d.ob.quart.

V - 26 februari - 63 chaldrons (6 lb. 6 s.) - 19 d.

43 - Willelmus Jacobsone - le Maryschippe de Neuhavene (zie nr 5) A -21 februari - appelen, meekrap en linnen (10 lb. $16 \mathrm{~s} .8 \mathrm{~d}$.) 2 s. 8 d.ob.

V - 24 februari - 58 chaldrons (113 s. 4 d.) - 17 d.

44 - Johannes Jacobsone - le Maryschippe de Neuhaven

A -21 februari - keukengerief en andere goederen (10 lb. $10 \mathrm{~s}$.) 2 s. 7 d.ob.

V - 24 februari - 48 chaldrons (4 lb. 16 s.) - 14 d.ob. 
45 - Deryng Bast - le Maryeschippe de Neuhavene A - 21 februari - keukengerief (9 lb. 10 s.) - 2 s. 4 d.ob.

47 - Johannes Rener $(a)$ - le Blitheleem de Lumbardye (Lombardsijde) (zie $\mathrm{nr}$ 120)

A -23 februari - appelen en bast (16 s. 8 d.) - 2 d.ob. $\mathrm{V}-26$ februari - een molensteen ( $3 \mathrm{~s} .4 \mathrm{~d}$.) - ob.

48 - Petrus Hallyng - le Maryeschippe de Lumbardye (zie nrs 86 en 119)

A - 23 februari - bast (16 s. 8 d.) - ob.

$\mathrm{V}-26$ februari - 44 chaldrons (4 lb. $8 \mathrm{~s}$.) - $13 \mathrm{~d}$.

49 - Michael Raskherd - le Wonder de Lumbardye $\mathrm{V}-3$ maart - 36 chaldrons (72 s.) - $11 \mathrm{~d}$.

50 - Johannes Sotherd - le Maryesschippe de Dunkirke $\mathrm{V}$ - 10 maart - 52 chaldrons en molenstenen (110 s.) - 16 d.ob.

57 - Matheus Hyne - le Maryschippe de Neuport

A - 4 april - tegels en andere koopwaar (13 s. 4 d.) - 2 d.

V - 10 april - 46 chaldrons (4 lb. 16 s.) - 14 d.ob.

58 - Jacobus More - le Nicholas de Neuport A -4 april - tegels (10 s.) - 1 d.ob.

V -10 april - 48 chaldrons (4 lb. $10 \mathrm{~s}$.$) - 13 \mathrm{~d} . \mathrm{ob}$.

59 - Clays Hane - le Laurence de Neuport

A - 4 april - tegels en andere goederen (20 s.) - 4 d.

61 - Johannes Damoder - le Cristofor del Haijs (zie nr 181)

A - 8 april - 6 bootmasten en andere goederen ( 66 s. 8 d.) - 10 d.

62 - Petrus de Cammera - le Godewille del Scluys V - 12 april - 70 chaldrons (7 lb.) - $21 \mathrm{~d}$.

63 - Willelmus Okke - le Crucemer del Scluys (zie nr 188) V - 12 april - 47 chaldrons en een molensteen (100 s.) - $15 \mathrm{~d}$.

64 - Christianus Cruce - le Katerine del Scluys V - 12 april - 52 chaldrons (103 s. 4 d.) - 15 d.ob.

65 - Ernaldus Hallyng - le Winpeny del Scluys $\mathrm{V}-12$ april - 57 chaldrons en een molensteen (6 lb.) - $18 \mathrm{~d}$.

67 - Ryke Reynman - le Maryschippe del Haijs (zie nr 107) V - 15 april - 45 chaldrons ( 4 lb. 10 s.) - 13 d.ob.

72 - Johannes Damoder - le Victor del Haijs (zie nr 183) A - 12 april - een pijp azijn (33 s. 4 d.) - 5 d.

77 - Stace Bouraven - le Cruceberghe de Dunkyrke (zie nr 178) V - 24 april - 46 chaldrons ( $4 \mathrm{lb} .12 \mathrm{~s}$.) - $14 \mathrm{~d}$.

79 - Jacobus Boressone - le Maryeschippe de Neuport (zie nr 175) V - 24 april - 46 chaldrons (4 lb. $12 \mathrm{~s}$ ) - $14 \mathrm{~d}$.

81 - Petrus Arnaldsone - le Maryeschippe del Haijs

A - 19 april - lamprei (10 s.) - 1 d.ob.

$\mathrm{V}-26$ april - 50 chaldrons (100 s.) - $15 \mathrm{~d}$. 
82 - Johannes Gylysone - le Maryeschippe del Haijs (zie nr 166) V - 26 april - 46 chaldrons (4 lb. $12 \mathrm{~s}$ ) - $14 \mathrm{~d}$.

85 - Johannes Clayssone - le Godewille del Haijs (zie nrs 105 en 138) V - 26 april - 50 chaldrons (100 s.) - 15 d.

86 - Petrus Hallyng - le Marieschippe de Lumbardye (zie nrs 48 en 119) V - 28 april - 48 chaldrons en een molensteen (106 s. 8 d.) - 16 d.

87 - Willemus Claissone - le Godewille del Haijs (zie nr 137) V - 28 april - 46 chaldrons (4 lb. $12 \mathrm{~s}$.) - $14 \mathrm{~d}$.

92 - Copyn Jonsone - le Marieschippe de Neuport $\mathrm{V}-12$ mei - 57 chaldrons (114 s.)

95 - Clays Halling - le Cristofor de Neuport (zie nr 177) $\mathrm{V}-12$ mei - 40 chaldrons (4 lb.) - $12 \mathrm{~d}$.

105 - Johannes Clayssone - le Godewille del Haijs (zie nrs 85 en 138) V - 11 juni - 47 chaldrons ( 4 lb. 13 s. 4 d.) - 14 d.

106 - Johannes Ffynche - le Cruceberghe de Wolrousyde (Walravensijde) (zie nrs 136 en 182) (b) V - 11 juni - 42 chaldrons (4 lb. 4 s.) - 12 d.ob.qu.

107 - Ryke Reynmanne - le Maryschippe del Haijs (zie nr 67) V - 11 juni - 48 chaldrons (c) (4 lb. 13 s. 4 d.) - 14 d.

108 - Egidius Soutersone - le Maryeschippe del Haijs V - 11 juni -45 chaldrons (4 lb. 10 s.) - 13 d.ob.

110 - Michaelis Grydoke - le Blitheleme de Dunkyrke V - 15 juni - 38 chaldrons (46 s. 8 d.) - 10 d.

111 - Jacobus Coveryng - le Cruceberghe de Dunkyrke (zie nr 174) V - 15 juni - 34 chaldrons (66 s. 8 d.) - $10 \mathrm{~d}$.

112 - Michaelis Jakemanne - le Maryschippe de Brugge $\mathrm{V}-15$ juni - 34 chaldrons en een molensteen (70 s.) - 10 d.ob.

113 - Petrus Guysne - le Godewille de Ostende (zie nr 193) V - 15 juni - 34 chaldrons ( 66 s. 8 d.) - 10 d.

115 - Baudewynus Wisteler - le Cruceberghe de Dunkyrke (zie nr 155) A -10 juni - 200 kruiken (6 s. 8 d.) -1 d.

$\mathrm{V}-20$ juni - 50 chaldrons (100 s.) - $15 \mathrm{~d}$.

117 - Boudyn Hallyng - le Juliane de Neuport (zie nr 172) A - 16 juni - zout en linnen ( $26 \mathrm{~s} .8 \mathrm{~d}$.) $-4 \mathrm{~d}$.

$\mathrm{V}-24$ juni - 36 chaldrons en een molensteen ( $4 \mathrm{lb} .3 \mathrm{~s} .4 \mathrm{~d}$.) 12 d.ob.

118 - Johannes Bukke - le Maryschippe de Dunkyrk A - 16 juni - wagenschot en tegels ( 30 s.) - 4 d.ob.

V -24 juni -80 chaldrons (7 lb. $16 \mathrm{~s} .8 \mathrm{~d}$.) - 23 d.ob.

119 - Petrus Hallyng - le Maryschippe de Lumbardye (zie nrs 48 en 86) A -20 juni - tegels (10 s.) - 1 d.ob. V -26 juni - 44 chaldrons (73 s. 4 d.) - 11 d.

120 - Johannes Rener - le Blitheleme de Lumbardye (zie nr 47) (a) A -20 juni - tegels (10 s.) - 1 d.ob. 
$\mathrm{V}-26$ juni - 40 chaldrons en een molensteen ( 4 lb. 6 s. 8 d.) $13 \mathrm{~d}$.

121 - Clays Halling - le Cristofor de Neuport $\mathrm{V}-28$ juni - 40 chaldrons (4 lb.) $-12 \mathrm{~d}$.

122 - Johannes Paw - le Maryschippe de Neuport $\mathrm{V}-28$ juni -48 chaldrons (4 lb. 13 s. 4 d.) -14 d.

125 - Johannes Clayssone - le Maryschippe de Neuhavene A -1 juli - linnen (20 s.) - 3 d.

126 - Jehannes Loure - le Maryschippe de Neuport V -4 juli -42 chaldrons ( 4 lb. 3 s. 4 d.) - 12 d.ob.

127 - Johannes Mewe - le Margaret de Neuport $\mathrm{V}-4$ juli - 54 chaldrons (106 s. 8 d.) - $16 \mathrm{~d}$.

129 - Jacobus Gasyn - le Maryschippe de Neuport (zie nr 163) A -4 juli - tegels (10 s.) - 1 d.ob.

$\mathrm{V}-10$ juli -45 chaldrons (4 lb. $10 \mathrm{~s}$ ) -13 d.ob.

130 - Petrus Mulard - le Maryschippe de Neuport A -4 juli - tegels (10 s.) - 1 d.ob.

V - 10 juli - 45 chaldrons (4 lb. $10 \mathrm{~s}$ ) - 13 d.ob.

131 - Johannes Gyner - le Maryschippe de Neuport A -4 juli - tegels (10 s.) - 1 d.ob.

V - 10 juli - 52 chaldrons (104 s.) - 15 d.ob.quart.

133 - Johannes Greunebusk - le Cristofor del Scluys V - 12 juli - 46 chaldrons (4 lb. 13 s. 4 d.) - 14 d.

134 - Arnaldus Gylramsone - le Maudeleyn del Scluys A - 10 juli - zout, teer en linnen (60 s.) - 9 d.

135 - Clays Gerard - Lightfote de Wolrausyde (zie nr 179) (b) $\mathrm{V}-14$ juli - 40 chaldrons (4lb.) - $12 \mathrm{~d}$.

136 - Jacobus Ffynche - le Crucebergh de Wolrausyde (zie nrs 106 en 182) (b)

$\mathrm{V}-14$ juli - 40 chaldrons (4 lb.) - $12 \mathrm{~d}$.

137 - Willelmus Clayssone - le Godewille del Haijs (zie nr 87) $\mathrm{V}-14$ juli - 40 chaldrons (4 lb.) - $12 \mathrm{~d}$.

138 - Johannes Clayssone - le Godwille del Haijs (zie nrs 85 en 105) $\mathrm{V}-14$ juli -48 chaldrons (100 s.) - $15 \mathrm{~d}$.

141 - Gerardus Jonsone - le Maryschippe del Haijs $\mathrm{V}-20$ juli - 58 chaldrons en een molensteen ( $6 \mathrm{lb} .6 \mathrm{~s}$.) $-19 \mathrm{~d}$.

143 - Boud Utersone - le Godtyde del Haijs V - 21 juli - 56 chaldrons (113 s. 4 d.) - 17 d.

144 - Petrus Clayssone - le Godwille del Haijs $\mathrm{V}-21$ juli -48 chaldrons (4 lb. $16 \mathrm{s.}$ ) - 14 d.ob.

149 - Johannes Sparauke - le Boye de Dunkirke

A - 18 juli - pek (20 s.) - 3 d.

V -24 juli -30 chaldrons (60 s.) $-9 d$. 
150 - Petrus Jacobsone - le Doubeler del Scluys V - 24 juli - 46 chaldrons (4 lb. 13 s. 4 d.) - 14 d.

151 - Michaelis Beuter - le Blitheleme de Dunkirke $\mathrm{V}-24$ juli -34 chaldrons (66 s. 8 d.) - $10 \mathrm{~d}$.

152 - Johannes Gourlayn - le Godwille del Estende (Oostende) $\mathrm{V}-26$ juli - 34 chaldrons (66 s. 8 d.) - 10 d.

155 - Bawdewynus Wespeler - le Cruceberghe de Dunkirke (zie nr 115) $\mathrm{V}-26$ juli - 50 chaldrons (100 s.) - $15 \mathrm{~d}$.

156 - Johannes de Luttone - le Cruceberghe de Dunkirke (zie nr 187) V - 26 juli - 42 chaldrons ( 4 lb. 6 s. 8 d.) en aardewerk - 13 s.

157 - Johannes Clayssone - le Blitheleme de Dunkirke V - 26 juli - 36 chaldrons (73 s. 4 d.) - 11 d.

158 - Willelmus Ffrelyng - le Maryschippe de Gravenynge (Grevelinge) (zie $\mathrm{nr}$ 196) (d)

V - 28 juli - 46 chaldrons (4 lb. 13 s. 4 d.) -14 d.

159 - Johannes de Luttone - le Blitheleme de Dunkirke V - 28 juli - 56 chaldrons (113 s. 4 d.) - 17 d.

160 - Johannes Louresone - le Cruceberghe de Neuport $\mathrm{V}-29$ juli - 40 chaldrons $(4 \mathrm{lb}$.) - $12 \mathrm{~d}$.

161 - Johannes Blancard - le Maryschippe de Neuport $\mathrm{V}-2$ augustus - twee vaten smout en 15 zakken hout $(50 \mathrm{~s}$.) 7 d.ob.

162 - Willelmus Boyde - le Maryschippe del Scluys (zie nr 164) A -2 augustus - zout en kurk (11 lb. 13 s. 4 d.) - 2 s. $11 \mathrm{~d}$.

163 - Jacobus Gosyn - le Maryschippe de Neuport (zie nr 129) $\mathrm{V}-2$ augustus - 44 chaldrons (4 lb. $6 \mathrm{~s} .8 \mathrm{~d}$.) - $13 \mathrm{~d}$.

164 - Willelmus Boyde - le Maryschippe del Scluys (zie nr 162) $\mathrm{V}-10$ augustus - 95 chaldrons ( $9 \mathrm{lb} .10 \mathrm{~s}$ ) $)$ - 2 s. 4 d.ob.

166 - Johannes Gylysone - le Maryschippe del Haijs (zie nr 82) $\mathrm{V}-10$ augustus - 45 chaldrons (4 lb. $10 \mathrm{~s}$.) - 13 d.ob.

167 - Johannes Riner - le Hauler de Lumbardye $\mathrm{V}-10$ augustus - 60 chaldrons (6 lb.) - $18 \mathrm{~d}$.

169 - Willelmus Pawe - le Maryschippe de Neuport $\mathrm{V}-12$ augustus - 40 chaldrons (4 lb.) - $12 \mathrm{~d}$.

170 - Copyn Gyfler - le Maryschippe de Neuport A -9 augustus - 4000 tegels (10 s.) - 1 d.ob. $\mathrm{V}-15$ augustus - 48 chaldrons (4 lb. $16 \mathrm{~s}$ ) $)-14$ d.ob.

171 - Mewes Hane - le Laurence de Neuport $\mathrm{V}-15$ augustus - 40 chaldrons (4 lb.) - $12 \mathrm{~d}$.

172 - Bawdewinus Halling - le Juliane de Neuport (zie nr 117) $V-15$ augustus - 30 chaldrons ( $60 \mathrm{~s}$.) - $9 \mathrm{~d}$.

173 - Johannes Covelyng - le Blitheleme de Lumbardye $\mathrm{V}-15$ augustus - 36 chaldrons (73 s. 4 d.) - $11 \mathrm{~d}$. 
174 - Jacobus Camerlyng - le Cruceberghe de Dunkirke V - 18 augustus - 34 chaldrons (66 s. 8 d.) - 10 d.

175 - Jacobus Bouresone - le Maryschippe de Neuport (zie nr 79) V - 18 augustus - 40 chaldrons (4 lb.) - $12 \mathrm{~d}$.

176 - Johannes Hallyng - le Maryshype de Lumbardie V - 19 augustus - 38 chaldrons (76 s. 8 d.) - 11 d.ob.

177 - Nicholaus Hallyng - le Cristofre de Neuport (zie nr 95) V - 19 augustus - 40 chaldrons (4 lb.) - $12 \mathrm{~d}$.

178 - Stace Bouraven - le Cruceberghe de Dunkirke (zie nr 77) V - 19 augustus - 36 chaldrons (73 s. 4 d.) - 11 d.

179 - Nicholaus Gerard - Lyghtfot de Wolrausyde (zie nr 135) (b) V - 19 augustus - 40 chaldrons (4 lb.) - $12 \mathrm{~d}$.

180 - Johannes Cotener - le Maryshyp de Hays $\mathrm{V}-19$ augustus - 50 chaldrons (100 s.) - $15 \mathrm{~d}$.

181 - Johannes Damoder - le Cristofre de Hays (zie nr 61) $\mathrm{V}-19$ augustus - 60 chaldrons $(6 \mathrm{lb}$.) $-18 \mathrm{~d}$.

182 - Jacobus Ffynk - le Cruceberghe de Wolrausyde (zie nrs 106 en 136) (b)

$\mathrm{V}-22$ augustus - 40 chaldrons (4 lb.) - $12 \mathrm{~d}$.

183 - Johannes Damoder - le Victor de Hays (zie nr 72) $\mathrm{V}-22$ augustus - 60 chaldrons $(6 \mathrm{lb}$.) $-18 \mathrm{~d}$.

186 - Johannes de Luttone - Cristofre de Dunkirke V -25 augustus - 46 chaldrons (4 lb. 13 s. $4 d$.) - $14 \mathrm{~d}$.

187 - Johannes Luttone - le Cruceberghe de Dunkirke (zie nr 156) $\mathrm{V}-25$ augustus - 40 chaldrons (4 lb.) - $12 \mathrm{~d}$.

188 - Willelmus Okke - le Cruceberghe del Scluys (zie nr 63) V - 26 augustus - 42 chaldrons (4 lb. 3 s. 4 d.) - 12 d.ob.

189 - Derynge Uterman - le Katerine de Dunkirke V - 26 augustus - 40 chaldrons (4 lb.) - $12 \mathrm{~d}$.

191 - Johannes Grydok - le Blythelem de Dunkyrke A -26 augustus - koopwaar en tegels (13 s. 4 d.) $-2 \mathrm{~d}$.

$\mathrm{V}-31$ augustus - 30 chaldrons (60 s.) - $9 \mathrm{~d}$.

192 - Petrus Lambe - le Cruceberghe de Dunkirke $\mathrm{V}-31$ augustus - 80 chaldrons (8lb.) - $2 \mathrm{~d}$.

193 - Petrus Wysloe - le Godwylle de Ostende (zie nr 113) $\mathrm{V}-31$ augustus - 30 chaldrons (60 s.) - $9 \mathrm{~d}$.

194 - Johannes Gerardsone - le Maryship de Neuport A - 3 september - wagenschot (60 s.) - 6 d. V - 3 september - 60 chaldrons (6lb.) - $18 \mathrm{~d}$.

195 - Willelmus Ffrelyng - le Maryshyp de Gravenynge (zie nr 158) V - 16 september - 46 chaldrons (4 lb. 13 s. 4 d.) - $14 \mathrm{~d}$.

196 - Johannes Hound - le Cruceberghe de Neuport V - 16 september - 66 chaldrons ( $5 \mathrm{lb} .12 \mathrm{~s}$.) - $20 \mathrm{~d}$. 200 - Ivone Jonessone - le Godwille de Neuhavene (zie nrs 18 en 19) 
A - (datum niet aangeduid) - meekrap en andere goederen ( $75 \mathrm{~s}$ ) - 11 d.ob.

\section{B. Noordnederlandse eenheden}

24 - Johannes Ertsone - le Cristofor de Sirice (Zierikzee) A - 8 november 1377 - 40 1/2 last «allec de Scone» (103 lb.) 25 s. 9 d.

25 - Johannes Monc - le Sconewether de Brele (Brielle) A - 8 november - 42 last «allec de Scone» (103 lb.) - 25 s. 9 d.

27 - Hugo Jacobson - le Godregod de Brele A - 18 december - «allec album de Scone» (87 lb. 10 s.) - 21 s. 10 d.ob.

28 - Reginaldus Lange - le Cristofor de Cuyk A - 23 december - «allec album» $(60$ s. $)$ - 9 d.

29 - Gydman FFrethe - le Maryknyght de Herdewyk (Harderwijk) A - 26 december - «allec album de Scone» $(85 \mathrm{lb}$.) - 21 s. $3 \mathrm{~d}$.

30 - Johannes Reynersone - le Palmedagh de Monstredamme (Amsterdam ?)

A - 26 december - «allec album de Scone» (6 lb. 6 s. 8 d.) - 19 d.

31 - Johannes Fier - le Cristofore de Breme (Bremen) A - 26 december - «allec album de Scone» (76 s.) - 11 d.ob.

(a) «Rener» : kan ook «Rover» gelezen worden, daar de letters e en o nagenoeg op dezelfde wijze geschreven staan, wat ook zo is voor de letters $\mathrm{n}$ en u. De letter $\mathrm{u}$ kan bovendien ook als v geïnterpreteerd worden, zoals in «Wolrausyde» : Walravensijde.

(b) Zie noot a.

(c) In de tekst staat weliswaar "pro xlviii mol(aribus) valor(is) iiii lb. $13 \mathrm{~s} .4 \mathrm{~d}$.», maar juist die waardeaanduiding toont aan dat daarmede evenveel «chaldrons» steenkolen bedoeld moeten geworden zijn en dat we dus met een lapsus te doen hebben. - Zie ook noot 9 .

(d) Blake, p. 17, nam verkeerdelijk «Gravenynge» voor Groningen. 